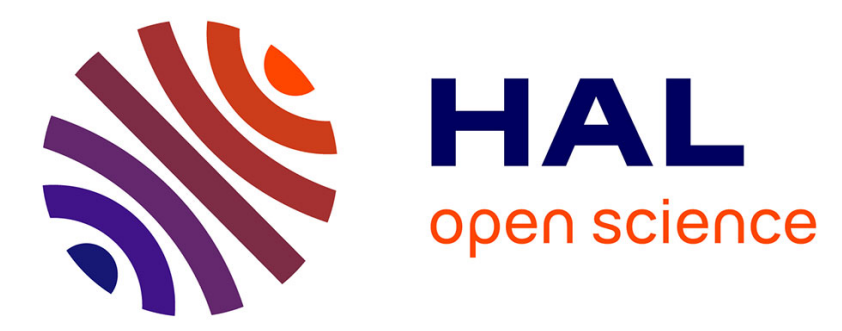

\title{
Thiabendazole/bentonites hybrids as controlled release systems
}

Graycyelle R.S. Cavalcanti, Maria G. Fonseca, Edson da Silva Filho, Maguy

Jaber

\section{- To cite this version:}

Graycyelle R.S. Cavalcanti, Maria G. Fonseca, Edson da Silva Filho, Maguy Jaber. Thiabendazole/bentonites hybrids as controlled release systems. Colloids and Surfaces B: Biointerfaces, 2019, 176, pp.249-255. 10.1016/j.colsurfb.2018.12.030 . hal-02169301

\section{HAL Id: hal-02169301 https://hal.sorbonne-universite.fr/hal-02169301}

Submitted on 1 Jul 2019

HAL is a multi-disciplinary open access archive for the deposit and dissemination of scientific research documents, whether they are published or not. The documents may come from teaching and research institutions in France or abroad, or from public or private research centers.
L'archive ouverte pluridisciplinaire HAL, est destinée au dépôt et à la diffusion de documents scientifiques de niveau recherche, publiés ou non, émanant des établissements d'enseignement et de recherche français ou étrangers, des laboratoires publics ou privés. 
3

4 5

6

7

8

9

10

11

12

13 14

15

16

17

18

19

20

21

22

23

24

25

26

27

28 The manuscript includes 4432 words, 6 figures and 2 tables

\section{systems} Jaber $*^{3}$ Branco III, 58051-085, João Pessoa - PB, Brazil. Teresina, Piaui, Brazil, France.

(15)

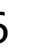

17

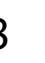

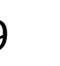

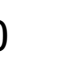

1

2

Graycyelle R. S. Cavalcanti ${ }^{1,3}$, Maria G. Fonseca ${ }^{1 *}$, Edson C. da Silva Filho ${ }^{2}$ and Maguy

${ }^{I}$ Núcleo de Pesquisa e Extensão - Laboratório de Combustíveis e Materiais (NPE LACOM). Universidade Federal da Paraíba, Cidade Universitária, s/n - Castelo

${ }^{2}$ Interdisciplinary Laboratory of Advanced Materials, CCN, UFPI, 64049-550, ${ }^{3}$ Sorbonne Université, Laboratoire d'Archéologie Moléculaire et Structurale, CNRS UMR 8220, Tour 23, 3ème étage, couloir 23-33, BP 225, 4 place Jussieu, 75005 Paris, 
- Thiabendazole intercalates in the interlamellar space of bentonite.

- The nature of the interlamellar cation influenced the adsorption capacity of bentonite.

- Release tests showed that part of the drugs are still adsorbed on the bentonites.

- The solids have shown to be promising for pharmaceutical applications.

\section{Abstract}

37 Clay minerals are commonly used in pharmaceutical products as excipients and active agents. New drug vehicles based on clay minerals have been developed. In this work, sodium (BentNa), calcium (BentCa) and magnesium (BentMg) exchanged bentonites were used for the sorption of thiabendazole (TBZ), and their potential use as controlled release systems was evaluated. Pristine bentonite and exchanged bentonites were characterized by X-ray diffraction, infrared spectroscopy, thermogravimetry and transmission electron microscopy (TEM), and the influence of the different parameters such as $\mathrm{pH}$, contact time and initial concentration of the drug was investigated. The maximum adsorption reached after 45 min period with $2000 \mathrm{mg} \mathrm{L}^{-1}$ of thiabendazole to 46 BentNa and after $105 \mathrm{~min}$ with $1300 \mathrm{mg} \mathrm{L}^{-1}$ to BentCa and BentMg, respectively. The 47 maximum adsorbed quantities of thiabendazole were $164.4 ; 152.3$ and $133.3 \mathrm{mg} \mathrm{g}^{-1}$ for 48 BentNa, BentCa and BentMg, respectively. The emission profiles obtained for the bentonite/drug hybrids were similar when simulated body fluids were used and these emission profiles were fitted according to the Korsmeyer-Peppas kinetic model.

Keywords: Clay minerals, Drug delivery system, thiabendazole, clay/drugs hybrids

57 The manuscript includes 4432 words, 6 figures and 2 tables 


\section{Introduction}

60 Clay minerals are an important class of natural materials which are used in 61 traditional medicine [1], their biological uses having been reported since antiquity. The medicinal properties of clay minerals have long been recognized in indigenous cultures, and their use in traditional medicine confined mainly to external applications for the treatment of skin problems and gastrointestinal diseases [2].

The specific physical and chemical properties of clay minerals such as adsorption, cation exchange capacity, swelling capacity, ability to form colloidal solutions, optimum rheological behavior and dispersibility in water [3-6] as also their low cost, abundance, biocompatibility versatility and effectiveness, have resulted, in recent decades, in the introduction of these minerals, into various technological processes [7-16] Clay minerals have therefore now been introduced as components in various pharmacological formulations, in which they are used as excipients. In addition to classic pharmaceutical uses, they can also be employed in the development of new drug delivery systems (DDS) [17-19]

Although all pharmaceutical dosage forms can be considered to DDS (since they use the administration of drugs intended to reach a site of action and maintain a certain concentration over the entire period of treatment), the final therapeutic effect of a pharmaceutical treatment will depend on several factors, which will involve the nature of the drug as well as the form taken for its administration and dosage [2,18]. Thus, the development of new technologies which aim to reduce the quantity of the administered

80 dose and decrease the levels of drug toxicity, has led to new controlled release systems 81 [20].

The formation of drug/clay mineral hybrids can influence the bioavailability of

83 the drug, the release rate, and the chemical stability of the systems [17]. For example,

84 stronger drug/bentonite interactions resulted in slower release and lower rates of drug 85 absorption and, in consequence, the reduction of the plasma concentration of the drug 86 [2,21]. These properties are not desirable for drugs such as antihistamines, which 87 require an immediate therapeutic concentration in the blood. Clay minerals are however 88 highly recommended as carriers for drugs that require slow and prolonged release, such 89 as antibiotics (amoxicillin, tetracycline, cephradine, metronidazole and gentamicin), 90 antihypertensive drugs (propranolol, nifedipine, amlodipine, etc.) and antipsychotics 91 (aripiprazole, buspirone) [22]. Thiabendazole (TBZ) is an anthelmintic and antifungal 92 drug used in the treatment of fungal and worm infections in animals and humans [23]. 
93 Four different TBZ species can be generated by protonation-deprotonation reactions

94 depending on the $\mathrm{pH}$ of the solution [24].

Previous studies have studied the adsorption of TBZ on Argentine clay, $[25,26]$. It was observed that there was a drastic reduction in TBZ adsorption when the

$97 \mathrm{pH}$ was changed from 5 to 7 , as a result of the presence of uncharged thiabendazole species. Moreover, at a $\mathrm{pH}$ lower than 2 , the ion exchange is the main mechanism of adsorption. Aluminum pillared montmorillonite was also used as a TBZ adsorbent in an aqueous medium [23,24].

The use of bentonite and thiabendazole for the development of controlled release systems has also been reported; Yasser (2014) used Ca-Bentonite in controlled release formulation of TBZ for reduced contaminations to soil water. Results showed that TBZ was better adsorbed in clay at the value $\mathrm{pH} 3$ and the release experiments showed that liberation the TBZ that slower at $\mathrm{pH} 3$ than at $\mathrm{pH} 5.5$ or $\mathrm{pH} 9$.

This present work focused on the study of the thiabendazole/bentonites system

107 for drug delivery, the aim being the investigation of the influence of the interlayer cations of bentonite on the interaction with thiabendazole. The kinetics of in vitro release of thiabendazole from hybrids in simulated gastric (SGF), body (SBF) and intestinal (SIF) fluids were also determined.

\section{2. Experimental}

\subsection{Material and chemicals}

The bentonite sample was donated by the Bentonisa do Nordeste SA in Brazil

115 (Boa Vista, PB).. The sample presented a cationic exchange capacity (CEC) of $88 \mathrm{cmol}$

$116(+) \mathrm{Kg}^{-1}$ and the following chemical composition - $\mathrm{SiO}_{2}(52.98 \%), \mathrm{Al}_{2} \mathrm{O}_{3}(18.35 \%)$, $117 \mathrm{Fe}_{2} \mathrm{O}_{3}(3.96 \%), \mathrm{MgO}(2.47 \%), \mathrm{Na}_{2} \mathrm{O}(2.56 \%), \mathrm{K}_{2} \mathrm{O}(0.22 \%)$, with a loss ignition of $118 \quad 18.59 \%$.

Thiabendazole (2-(thiazol-4-yl) benzimidazole, $\mathrm{M}=201.3 \mathrm{gmol}^{-1}$, $\mathrm{pKa} 2.5$,

1204.7 and 12.0), was acquired from Sigma-Aldrich, (99\% anaytical grade). Thiabendazole

121 is partially soluble in water $\left(28 \mathrm{mg} \mathrm{L}^{-1}\right)$ and soluble in acid solutions at low 122 concentrations; [23, 25, 26], a solution of the drug was therefore prepared with $3000 \mathrm{mg}$ $123 \mathrm{~L}^{-1}$ drug solution in $0.01 \mathrm{~mol} \mathrm{~L}^{-1} \mathrm{HCl}$. All the samples prepared were dried at $343 \mathrm{~K}$ for $12448 \mathrm{~h}$ and then conducted for characterization. 
126 Raw bentonite (Bent) was purified to remove quartz by the centrifugation 127 decantation method. The sample was suspended in $1.0 \mathrm{~mol} \mathrm{~L} \mathrm{~L}^{-1} \mathrm{NaCl}, \mathrm{CaCl}_{2} .2 \mathrm{H}_{2} \mathrm{O}$ or $128 \mathrm{MgCl}_{2} \cdot 6 \mathrm{H}_{2} \mathrm{O}$ solutions, and was mantained under orbital agitation at $300 \mathrm{~K}$. The same 129 procedure was repeated twice to guarantee the process of ion exchange [3]. The 130 exchange samples were named BentNa, BentCa and BentMg.

\subsection{Sorption of thiabendazole}

We first monitored the influence of $\mathrm{pH}$ on the drug-bentonites interaction. 133 Samples of $200 \mathrm{mg}$ of each exchange solid was suspended in $50.0 \mathrm{~mL}$ of $500 \mathrm{mg} \mathrm{L}^{-1}$ 134 drug solution, and the $\mathrm{pH}$ was adjusted to $1.4,2.3$ and 3.8, the values of which were 135 determined based on the pKa of thiabendazole. The suspension was stirred for a period 136 of $24 \mathrm{~h}$. The final solids were centrifuged, and the thiabendazole in equilibrium solution was quantified by UV-Vis molecular spectrometry in an UV-Vis spectrofotometer Shimadzu model 2550, at $298 \mathrm{~nm}$ in the concentration range of $2-8 \mathrm{mg} \mathrm{L}^{-1}$.

$$
q_{e}=\frac{\left(C_{0}-C_{e}\right) V}{m}
$$

Where $\mathrm{C}_{0}$ and $\mathrm{C}_{\mathrm{e}}$ are the drug concentration $\left(\mathrm{mg} \mathrm{L}^{-1}\right)$ in solution before and after sorption respectively, $\mathrm{V}(\mathrm{L})$ is the volume of the drug solution, and $\mathrm{m}(\mathrm{g})$ is the mass of 144 the bentonite.

145 To investigate the influence of time on adsorption, the same procedure was used, and the time was varied between 0 and $120 \mathrm{~min}$ in the same conditions.

The effect of the initial concentration of the drug was monitored by using thiabendazole at 30 and $3000 \mathrm{mg} \mathrm{L}^{-1}$, which reacted with bentonites at optimum conditions for both $\mathrm{pH}$ and time.

\subsection{Synthesis of bentonite/drug hybrids}

The synthesis of the hybrids was carried out basing oneself on the previous

152 conditions of $\mathrm{pH}$, time and drug concentration, as determined in the adsorption tests.

153 Therefore, a $1.0 \mathrm{~g}$ sample of each bentonite category was suspended in $250 \mathrm{~mL}$ of 2000

$154 \mathrm{mg} \mathrm{L}^{-1}$ drug solution, and then reacted for a period of $45 \mathrm{~min}$ in the case of the sodium 
155 bentonite, and for the calcium and magnesium samples, $1.0 \mathrm{~g}$ of each solid was reacted 156 with the $1300 \mathrm{mgL}^{-1}$ drug solution for $105 \mathrm{~min}$. The systems were maintained under 157 orbital agitation at $300 \mathrm{~K}$. Finally, the drug concentration was determined as described 158 above.

159

For the release test, simulated gastric (SGF, $\mathrm{HCl}$ aqueous solution, $\mathrm{pH} 1.2$ ), body (SBF, pH 7.4) and intestinal (SIF, phosphate buffer solution, $\mathrm{pH}$ 7.4) fluids were

163 prepared. The SBF was prepared by dissolving the following chemical reagents in $1.0 \mathrm{~L}$ 164 distilled water: $\mathrm{NaCl}(7.996 \mathrm{~g}), \mathrm{NaHCO}_{3}(0.350 \mathrm{~g}), \mathrm{KCl}(0.224 \mathrm{~g}), \mathrm{K}_{2} \mathrm{HPO}_{4} .3 \mathrm{H}_{2} \mathrm{O}$ 165 (0.228 g), $\left.\mathrm{MgCl}_{2} \cdot 6 \mathrm{H}_{2} \mathrm{O}(0.305 \mathrm{~g}), \mathrm{CaCl}_{2}(0.278 \mathrm{~g}), \mathrm{Na}_{2} \mathrm{SO}_{4}(0.071 \mathrm{~g}), \mathrm{NH}_{2} \mathrm{C}_{(\mathrm{CH}} \mathrm{OH}\right)_{3}$ $166(6.057 \mathrm{~g})$ [27]. The release test followed standard procedure where $0.1 \mathrm{~g}$ of each solid 168 BentNaTBZ, BentCaTBZ and BentMgTBZ was suspended as a disk in $400 \mathrm{~cm}^{3}$ of each 169 fluid. The system was mantained at $335 \mathrm{~K}$ for $72 \mathrm{~h}$, and at each time interval, aliquots of $1705.0 \mathrm{~mL}$ of the solution were removed, and the same volume of drug solution then added 171 to the suspension [28].

172 The drug concentration was quantified as described above. The cumulative 173 drug concentration was calculated $\left(\mathrm{C}_{\mathrm{c}}\right)$ as determined in Equation (2), where $\mathrm{C}_{\mathrm{f}}\left(\mathrm{mg} \mathrm{L}^{-1}\right)$ 174 is the final drug concentration in solution, $\mathrm{V}_{\mathrm{f}}$ and $\mathrm{V}_{\mathrm{a}}(\mathrm{L})$ are the volumes of fluid and 175 alíquota, respectively.

$$
C_{c}=C_{f}+\frac{\left(V_{a} * C_{f}\right)}{V_{f}}
$$

\section{3. Results and discussion}

\subsection{Characterization of exchanged bentonites}

For raw bentonite, the XRD patterns of the samples (SM1) exhibited the 181 principal montmorillonite reflection at $2 \theta 7.24^{\circ}\left(\mathrm{d}_{001}=1.22 \mathrm{~nm}\right)$ [30]. Other reflections 182 were observed at $2 \theta 19.8^{\circ} ; 28.5^{\circ} ; 34.9^{\circ}$ and $61.8^{\circ}$ and were indexed to montmorillonite 183 phase in agreement with ICDD file 00-060-0318. The additional peaks at $2 \theta 11.7^{\circ}$ and 
$18426.5^{\circ}$ were associated to muscovite and quartz phases, respectivelly. After removal of 185 the quartz, the XRD patterns maintained the reflections of montmorillonite, and the 186 quartz peaks were not observed. After ion exchange, the samples displayed reflections at $7.55^{\circ}, 6.19^{\circ}$ and $6.17^{\circ}$ 188 associated to the (001) plan with basal spacings of 1.17, 1.43 and $1.43 \mathrm{~nm}$ for BentNa, 189 BentMg and BentCa respectively. These values are in agreement with those observed 190 for natural sodium [30], calcium [31] and magnesium montmorillonites [32]. In the Bent 191 and BentNa samples, an additional peak at $28.4^{\circ}$ is attributed to the presence of residual $192 \mathrm{NaCl}$ in according ICDD file 01-083-1728. The higher values of the basal spacings were 193 those obtained for samples with higher hydration cation volume, 156.7 and $176.9 \mathrm{~cm}^{3}$ $194 \mathrm{~mol}^{-1}$ for $\mathrm{Ca}^{2+}$ and $\mathrm{Mg}^{2+}$, and $109.0 \mathrm{~cm}^{3} \mathrm{~mol}^{-1}$ for $\mathrm{Na}^{+}$.

195 FTIR spectra (Figure 1ii) for all samples displayed bands at $3634 \mathrm{~cm}^{-1}$, assigned 196 to structural $\mathrm{OH}$ stretching (M-OH, $\mathrm{M}=\mathrm{Al}^{3+}, \mathrm{Mg}^{2+}, \mathrm{Fe}^{3+}$ ), and at $3400 \mathrm{~cm}^{-1}$ resulting 197 from $\mathrm{OH}$ stretching of interlayer water and silanol $(\mathrm{Si}-\mathrm{OH})$; the $\mathrm{OH}$ stretching of water, 198 however, showed a small variation which can be related to the interlayer cation. The 199 band associated to the bending of water was observed at $1642 \mathrm{~cm}^{-1}[33,34]$. Other bands 200 were detected at 1121 and $1040 \mathrm{~cm}^{-1}$ and assigned to Si-O assymetric and symmetric 201 stretchings, respectively. Si-O-Al and Si-O-Si bending vibrations, were detected at 523 202 and $461 \mathrm{~cm}^{-1}$ respectively. Isomorphic substitution of $\mathrm{Al}^{3+}$ for $\mathrm{Mg}^{2+}$ and $\mathrm{Fe}^{2+}$ in the 203 octahedral sheet provokes changes in the $\mathrm{OH}$ deformation bands at $918 \mathrm{~cm}^{-1}$ (Al-Al$204 \mathrm{OH}), 876 \mathrm{~cm}^{-1}(\mathrm{Al}-\mathrm{Fe}-\mathrm{OH})$ and $830 \mathrm{~cm}^{-1}(\mathrm{Al}-\mathrm{Mg}-\mathrm{OH})$, and these were dependent on the 205 nature of the cation present $[35,36]$. 

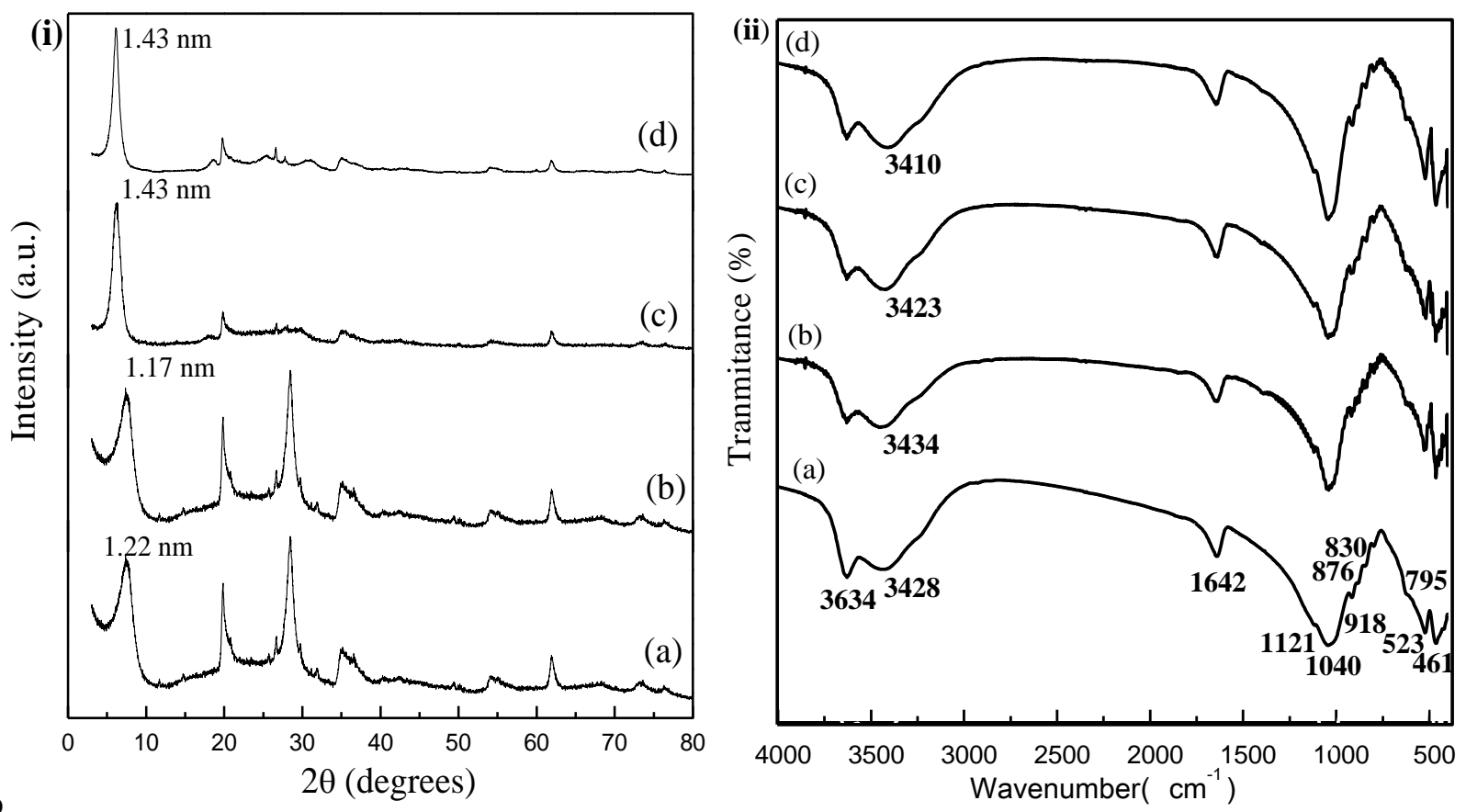

206

Figure 1 i) XRD patterns and ii) FTIR spectra for (a) Bent, (b) BentNa, (c) BentCa and 208 (d) BentMg.

In the DTG curves for BentNa, BentCa and BentMg (Figure SM2), two mass 210 losses were observed: at $298-660 \mathrm{~K}$ and at $660-1200 \mathrm{~K}$ for BentNa.. The first is related 211 to the loss of physically adsorbed water and interlayer water, and the second is the result 212 of the dehydroxilation and loss of the coordination water. In the instance of the 213 magnesium and calcium bentonites, three mass losses were observed, at 298-573,573$214754 \mathrm{~K}$ and 754-1200 K for BentCa, and at 298-483 K, 483-748 K and 748-1200 K for 215 BentMg. As above, the first loss is related to the loss of adsorbed and interlayer waters, 216 and the second and third ones can be assigned to the dehydroxilation and loss of 217 coordination water, respectively. [30,37]

\subsection{Sorption of thiabendazole}

219 The effect of $\mathrm{pH}$ on thiabendazole sorption onto BentNa, BentCa and BentMg 220 (Figure 2), showed a maximum sorption of $114 \mathrm{mg} \mathrm{g}^{-1}$ for all $\mathrm{pH}$ values. Therefore, the 221 value of 1.4 was used in all experiments. The thiabendazole molecules are present at 92 $222 \%$ for $\mathrm{TBZ}^{++}$species $(\mathrm{pKa}=2.5)$ and $99.9 \%$ for $\mathrm{TBZ}^{+}(\mathrm{pKa}=4.7)$. The sorption of 223 thiabendazole is usually $\mathrm{pH}$-dependent [26]. For protonated TBZ (TBZ ${ }^{+}$), the sorption 224 onto bentonite occured by ion exchange between the inorganic cation in the interlayer 225 space and the organic one, $\mathrm{TBZ}^{+}[38]$. 


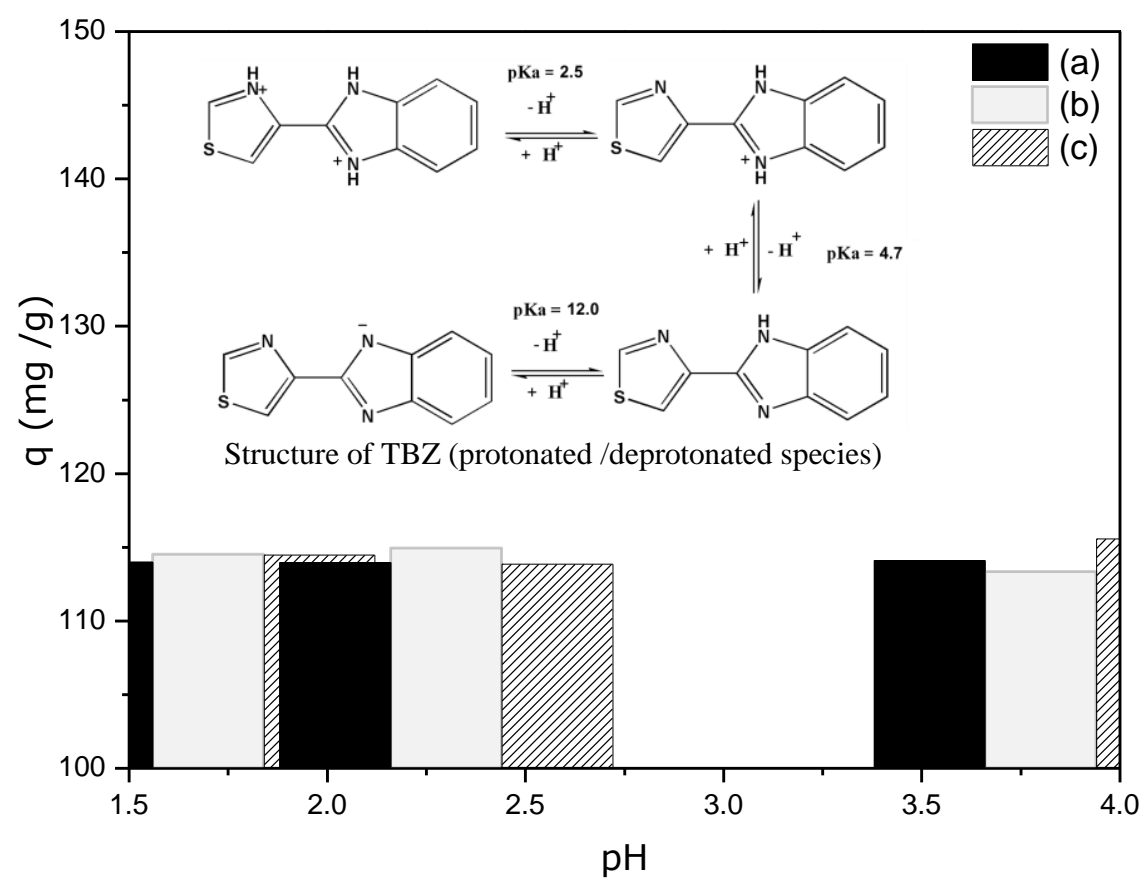

226

Figure 2. The effect of $\mathrm{pH}$ on thiabendazole adsorption onto (a) BentNa, (b) BentCa and

228 (c) BentMg at $300 \mathrm{~K}$. Inserted figure is that of the TBZ structure.

229 The influence of contact-time on sorption of thiabendazole onto bentonites 230 (Figure 3i), displayed equilibrium at 30, 90 and $75 \mathrm{~min}$ where the maximum sorption 231 capacities were 115.5; 111.5 and $111.6 \mathrm{mg} \mathrm{g}^{-1}$ for BentNa, BentCa and BentMg 232 respectively. The data were fitted to second order kinetics (Figure SM3 and Table 1).

233 The equilibrium isotherms (Figure 3ii) show that the maximum adorbed 234 quantities are observed at a $2000 \mathrm{mg} \mathrm{L}^{-1}$ for Na-Bent with185 $\mathrm{mgg}^{-1}$ of Thiabendazole, 235 while for CaBent and $\mathrm{Mg}$-Bent $163 \mathrm{mg} \mathrm{g}^{-1}$ were adsorbed from a starting concentration 236 of $1300 \mathrm{mg} \mathrm{L}^{-1}$. The experimental data were better fitting to the Langmuir than the 237 Freundlich model (Figures SM4.1 and SM4.2), and the resulting parameters are 238 presented in Table 1. 

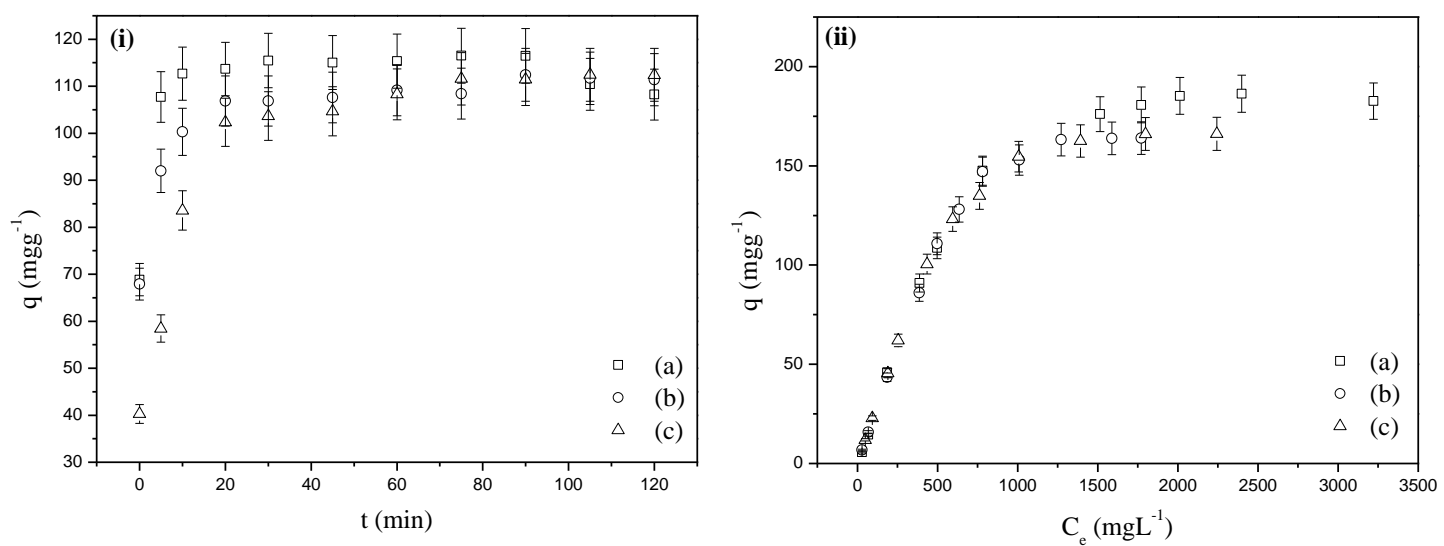

239

240 Figure 3. i) Effect of time and ii) initial drug concentration on thiabendazole adsorption

241 on (a) BentNa (b) BentCa and (c) BentMg at $300 \mathrm{~K}$ and $\mathrm{pH} 1.4$.

2423.3 Caracterization of thiabendazole/bentonite hybrids

243 CHN elemental analysis gave the following results: $164.4 ; 152.3$ and $133.3 \mathrm{mg}$

$244 \mathrm{~g}^{-1}$ of the drug on BentNaTBZ, BentCaTBZ and BentMgTBZ, respectively. XRD 245 patterns (Figure SM5) showed basal spacings altered from $1.17 \mathrm{~nm}$ to $1.42 \mathrm{~nm}$ in 246 BentNaTBZ, $1.52 \mathrm{~nm}$ to $1.41 \mathrm{~nm}$ in BentCaTBZ, and $1.43 \mathrm{~nm}$ to $1.39 \mathrm{~nm}$ in 247 BentMgTBZ. In other words, while for the sodium sample the basal spacing had a 248 higher value, the values decreased for the other two samples, suggesting some loss of 249 water in the intercalation of the organic molecule.

250 TEM micrographs (Figure 4, Figure SM6) suggested the typical layered 251 arrangement of pristine bentonites with interlayer spacings of 1.15-1.23 nm for BentNa; 252 1.44-1.56 nm for BentCa and 1.41-1.49 for BentMg. The solids saturated with the drug 253 presented a similar morphology [31,39] and the interplanar spacings were 1.31-1.47 nm 254 for BentNaTBZ, BentCaTBZ and BentMgTBZ, this data in agreeement with the XRD 255 patterns (Figure 4). 

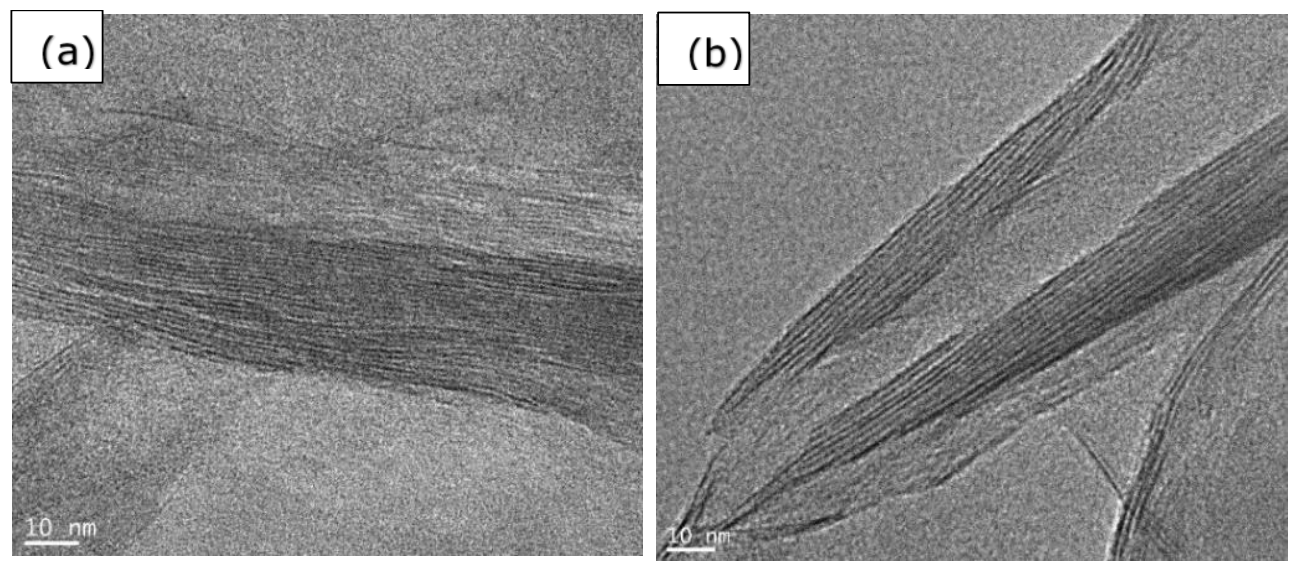

257 Figure 4. TEM micrographs of (a) BentNa and (b) BentNaTBZ

258

259

260

261

262

263

264

265

266

267

268

269

270

271

272

273

274

275

276

277

278

Taking into consideration the size of thiabendazole $(1.15 \mathrm{~nm} \times 0.72 \mathrm{~nm} \times 0.34$ $\mathrm{nm})$ [25], the thickness of the montmorillonite $(1.35 \mathrm{~nm})$ [30] the XRD patterns and TEM images, the interaction of thiabendazole and bentonite can be seen to be in preponderance through an ion exchange mechanism, involving also the intercalation of the protonated drug in the inter-layer spacing of montmorillonite [26,27].

The FTIR spectra of the hybrids presents typical bands of the free drug (Figure SM7). However, the bands assigned to C-N and N-H have shifted from 1306 to 1313 $\mathrm{cm}^{-1}$ possibily as a result of the protonation of the nitrogen of the benzimidazole group, and from 1574 to $1603 \mathrm{~cm}^{-1}$, suggesting the presence of the $\mathrm{TBZ}^{+}$and $\mathrm{TBZ}^{++}$forms on the bentonite $[27,40]$.

UV-VIS spectra for the exchanged samples BentNa, BentCa and BentMg (Figura SM8) displayed a broadadsorption at $250-300 \mathrm{~nm}$, assigned to $\mathrm{O} \rightarrow \mathrm{Si}$ and $\mathrm{O} \rightarrow \mathrm{Al}$ charge transfer bands [41]. After drug loading, a band centred at $298 \mathrm{~nm}$ was detected and this was the same as that observed for the free drug, which is associated to the $\mathrm{n}-\pi$ and $\pi-\pi^{*}$ molecular orbitals of the TBZ.

\subsection{Release test}

The release of thiabendazole from hybrids at the solid/liquid interface involved a number of processes which promote the transport of the drug from the solid to the liquid phase. Specifically, for clay minerals, diffusion is relevant and includes drug desorption from the external surface, and the loss of the intercalated molecules from the interlayer region [18]. 
$280 \mathrm{~h}$ in the simulated fluids (Figure 5), indicate a similar behavior with a release of 20, 27 281 and $17 \%$ in the first $9 \mathrm{~h}$ for BentNaTBZ; 14, 21 and $27 \%$ for BentCaTBZ and 18, 34 282 and $32 \%$ for BentMgTBZ SGF, SIF and SBF fluids, respectively. The slow and 283 controlled release is associated to cationic exchange between the intercalated charged 284 drug and the alkaline cations from the simulated fluids [42]
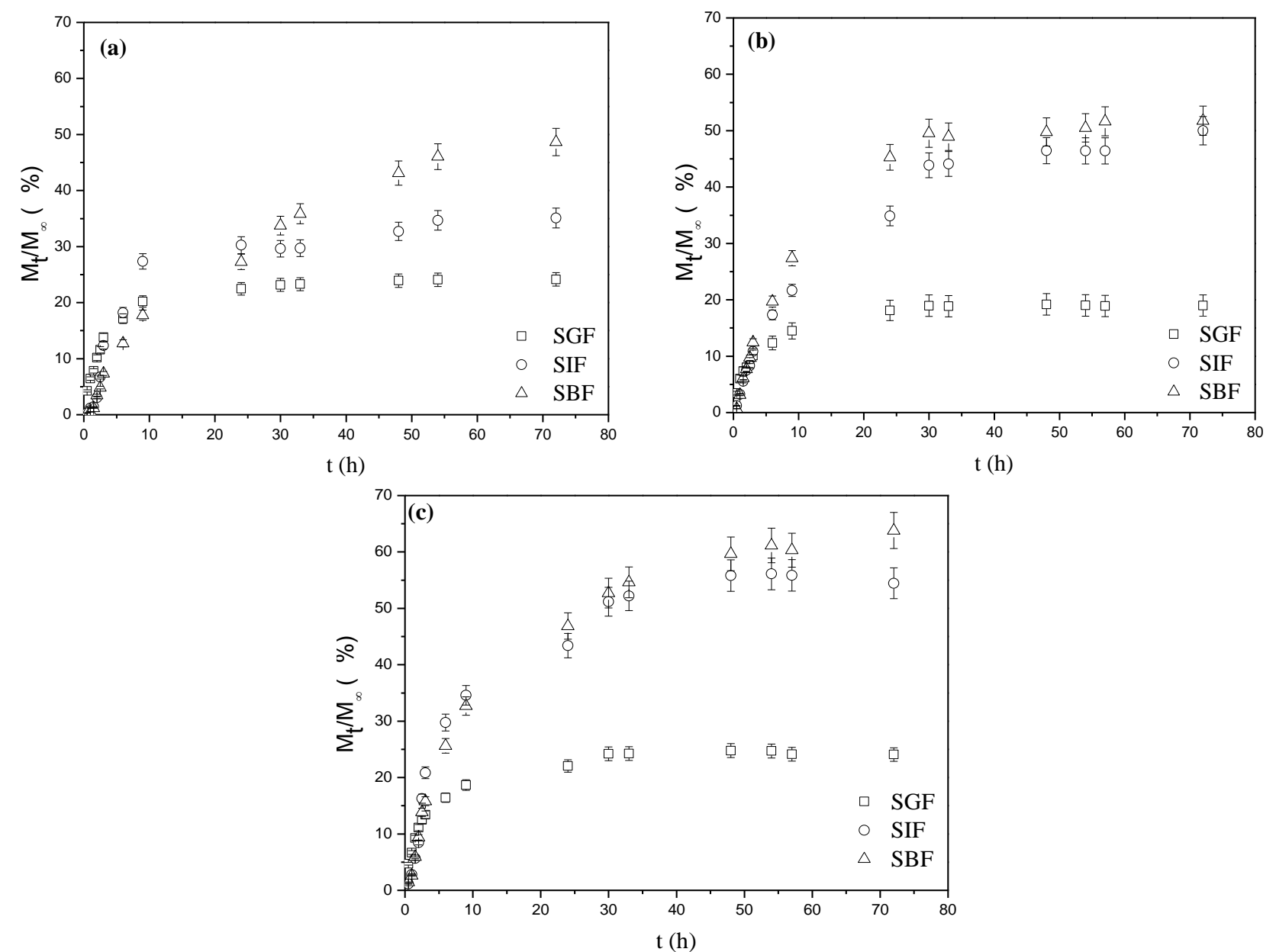

Figure 5. Cumulative release profiles of (a) BentNaTBZ, (b) BentCaTBZ and (c)

\section{BentMgTBZ}

290 equilibrium process in the ion exchange which is a complete reaction [42]. Futhermore,

291 electrostatic interaction between the cations and the anionic charge of the 292 montmorillonite results in incomplete release [43].

293 The release data were ajusted to Korsmeyer-Peppas model (Equation 3), 


$$
\frac{M_{t}}{M_{\infty}}=k t^{n}
$$

Where $M_{t} / M_{\infty}$ is the fractional release of the drug at time $t$, and $k$ and $n$ kinetic constants. The $\mathrm{n}$ value is used to characterize the principal mechanism of drug release; where release is Fickian diffusion when $\mathrm{n} \leq 0.45$, if $0.45 \leq \mathrm{n} \leq 0.89$, it indicates anomalous (non-Fickian) transport, if $\mathrm{n}=0.89$ the release follows case II and $\mathrm{n}>0.89$ super case II transport [44]

The obtained kinetic parameters (Figure SM9) for the system under investigation are presented in Table 2 .

The values of $\mathrm{R}^{2}$ indicate a good adjustment of the data for BentMgTBZ and

303 BentCaTBZ in the three simulated fluids. The $\mathrm{n}$ values were in the range of $0.45<\mathrm{n}<$ 3040.89 for the release in SGF in all systems, indicating that diffusion and erosion were the main mechanisms at play in the kinetic process of release. It is important to note that this model was proposed for polymers, and therefore the erosion cannot be considered reasonable for a clay mineral matrix [46]

For the TBZ release SIF and SBF, the values of $n$ were 0.89 suggesting that the kinetics of the reaction are based on a super case II transport mechanism, where the diffusion rate of the solvent is higher than the relaxation rate, and the drug release mechanism occurs as a result of swelling and stresses [47].

The XRD patterns of the solids after the release test (Figure SM10) showed that

313 the basal spacings were lower than the initial values observed for the loaded samples: ie.

$3141.42 \mathrm{~nm}$ for Bent $\mathrm{Na}, 1.41 \mathrm{~nm}$ for BentCa, and $1.39 \mathrm{~nm}$ for BentMg, suggesting the 315 presence of the unreleased drug in the final solids.

\section{4. Conclusion}

Thiabendazole was loaded onto three exchanged bentonites at different

319 conditions of equilibrium for $45 \mathrm{~min}$ and at an initial drug concentration of $2000 \mathrm{mgL}^{-1}$ 320 for BentNa, and for $105 \mathrm{~min}$ at an initial drug concentration of $1300 \mathrm{mgL}^{-1}$ for BentCa and BentMg.

The loaded solids behaved as good drug in vitro release systems in simulated 323 fluids, with SBF having the highest release of the three samples. The BentMgTBZ 
324 system exhibited the highest cumulative release compared with the other samples. The

325 thiabendazole release kinetics of the drug/bentonite hybrids were similar, and adjusted 326 to the Korsmeyer-Peppas model.

327 The different tests demonstrated that the nature of the interlayer cation in 328 bentonite influenced the thiabendazole loading and release quantities, and that it is a key 329 parameter that should be considered in the application of bentonites as vehicles for 330 drugs.

\section{Acknowledgments}

CNPq is acknowledged for research fellowships to M.G. Fonseca and E.C. Silva

333 Filho. G.R.S. Cavalcanti thanks to CAPES for providing research fellowship.

334 CAPES/COFECUB (835/2015) for financial support.

\section{References}

336

337

338

339

340

341

342

343

344

345

346

347
1. Abrahams P. W. Involuntary Soil ingestion and geophagia: a source and sink of mineral nutrients and potentially harmful elements to consumers of earth materials. Applied Geochemistry, 2012, 27,954-968.

2. Ghadiri. M., Chrzanowski. W., Rohanizadeh. R. Biomedical applications of cationic clay minerals. Royal Society of Chemistry, 2015, 5, 37, 29467-29481.

3. Bergaya. F. Lagaly. G. General Introduction: Clays. Clay Minerals and Clay Science. In: Bergaya. F. Theng. B. K. G. Lagaly. G. Eds., Handbook of Clay Science. Elsevier. Amsterdam. Developments in clay science, 2013, 5,1-19.

4. Brigatti. M. F., Galán. E., Theng. B. K. G. Structure and mineralogy of clay minerals. In: Bergaya. F. Theng. B. K. G. Lagaly. G. Eds., Handbook of clay science. Elsevier. Amsterdam. Developments in clay science, 2013, 5,21-81.

5. Tangaraj, V.et al., Adsorption and phytophysical properties of fluorescent dyes over montmorillonite and saponite modified by surfactant, Chemosphere, 2017, $184,1355-1361$. 
6. Jaber, M.et al. Selectivities in adsorption and peptidic condensation in the (arginine and glutamic acid)/montmorillonite clay system, J. The Journal of Physical Chemistry C, 2014,118 (44), 25447-25455.

7. He. H. et al. Silylation of clay mineral surfaces. Applied Clay Science, 2013,71, 15-20.

8. Fournier, F. et al. Physico-chemical characterization of lake pigments based on montmorillonite and carminic acid, Applied Clay Science, 2016, 130, 12-17.

9. Gomes, S.S. et al. Silylation of leached-vermiculites following reaction with imidazole and copper sorption behaviour, Journal of hazardous materials, 2016, 306, 406-418.

10. Trigueiro, P.et al. Going through wine fining : intimate dialogue between organics and clays, under revision, Colloids and surfaces b : biointerfaces, 2018, $166,12018,79-88$.

11. Zhuang, G. et al. Enhancing the rheological properties and thermal stability of oil-based drilling fluids by the synergetic use of organo-montmorillonite and organo-sepiolite, 2018, Applied Clay Science, 2018, 161, 505-512.

12. Guillermin,D. et al. New Pigments Based On Carminic Acid And Smectites, A Molecular Investigation, Pigments And Dyes, 2019, 160,971-982.

13. Trigueiro,P. et al.Intimate dialogue between anthraquinone dyes and pillared clay minerals, Pigments and dyes, 2018, 159, 384-394. montmorillonite and organo-palygorskite in oil-based drilling fluids, Journal of industrial and chemical engeneering, 2017, 56, 248-257. 
15. Pereira, F. A.R., et al. Green biosorbent based on chitosan-montmorillonite beads for anionic dyes removal, Journal of Environmental Chemical Engineering, 2017, 4(5), 3309-3318.

16. El Adraa, K. et al. Montmorillonite-cysteine composites for heavy metal cation complexation: a combined experimental and theoretical study, Chemical Engeneering Journal, 2017, 314, 406-417.

17. Rodrigues. L. A. De S. et al. The Systems containing clays and clay minerals from modified drug release: a review. Colloids and Surfaces B: Biointerfaces, 2013, 103,642-651.

18. Viseras. C. et al. Current challenges in clay minerals for drug delivery. Applied Clay Science, 2010, 48,3, 291-295.

19. Bouaziz, Z. et al. dual role of layered double hydroxide nanocomposites on antibacterial activity and degradation of tetracycline and oxytetracyline, Chemosphere, 2018, 2016, 175-183.

20. Shen. J.et al. Mucoadhesive effect of thiolated peg stearate and its modified nlc for ocular drug delivery. Journal of Controlled Release,2010,137,217-223.

21. Ruiz- Hitzky. E., Aranda. P., Darder. M. Hybrid and biohybrid materials based on layered clays. In: Brunet. E., Colón. J. L., Clearfield A. Eds. Tailored Organic-Inorganic Materials,Wiley, 2015, 245-297.

22. Yang. J. H. et al. Drug-Clay nanohybrids as sustained delivery systems. Applied Clay Science,2016,130, 20-32.

23. Roca Jalil. M. E. et al. Improvement in the adsorption of thiabendazole by using aluminum pillared clays. Applied Clay Science, 2013, 71,55-63. aluminum pillared clays. Applied Clay Science,2014, 87, 245-253. 
25. Yasser Z. E-N. Development of controlled release formulations of thiabendazole

400

401

402

403

404

405

406

407

408

409

410

411

412

413

414

415

416

417

418

419

420

421

422 Journal of Agricultural Chemistry and Environment,2014,3,1-8.

26. Lombardi. B., Baschini. M., Torres Sánchez. R. M. Optimization of parameters and adsorption mechanism of thiabendazole fungicide by a montmorillonite of north Patagonia. Applied Clay Science, 2003, 24, 1-2, 43-50.

27. Lombardi. B. M. et al. Interaction of thiabendazole and benzimidazole with montmorillonite. Applied Clay Science,2006, 33, 1, 59-65.

28. Xu, W. et al. Controllable release of ibuprofen from size-adjustable and surface hydrophobic mesoporous silica spheres. Powder Technology, 2009,191,1-2, 1320.

29. Joshi, G. V. et al. Montmorillonite as a drug delivery system: intercalation and in vitro release of timolol maleate. International Journal of Pharmaceutics,374, $1-2,53-57,2009 a$.

30. Lagaly, G., Ogawa, M., Dékány, I. Clay Mineral-Organic. Em: Bergaya, F., Theng, B. K. G., Lagaly, G., Eds., Handbook of Clay Science. Elsevier, Amsterdam. Developments In: Clay Science, 2013,5, 435-505.

31. Sun. Z. et al. XRD, TEM and Thermal analysis of Arizona ca-montmorillonites modified with didodecyldimethylammonium bromide. Journal of Colloid and Interface Science, 2013, 408,1,75-81.

32. Paz, S. P. A., Angélica, R. S., De Freitas Neves, R. Mg-bentonite in the parnaíba paleozoic basin, northern Brazil. Clays and Clay Minerals, 2012, $60,3,265-277$.

33. Madejová. J. FTIR Techniques in clay mineral studies. Vibrational Spectroscopy, 2003,31, 1,1-10. 
34. Tyagi. B., Chudasama. C. D., Jasra. R. V. Determination of structural modification in acid activated montmorillonite clay by FT-IR spectroscopy. Spectrochimica Acta - Part A: Molecular and Biomolecular Spectroscopy,2006, $64,2,273-278$.

35. Wu, L. M. et al. Fourier Transform Infrared spectroscopy analysis for hydrothermal transformation of microcrystalline cellulose on montmorillonite. Applied Clay Science,2014, 95,74-82.

36. Petit. S., Madejova J.Fourier Transform Infrared Spectroscopy. In: Bergaya. F. Theng. B. K. G. Lagaly. G. Eds., Handbook of Clay Science. Elsevier. Amsterdam. Developments in Clay Science, 2013, 5,213-231.

37. Földvári. M. Handbook of The Thermogravimetric system of minerals and its use in geological practice. Central European Geology, 2011,56, 1-179.

38. Roca Jalil. E. Desarrollo de arcillas pilareadas con al a partir de una bentonita natural de la norpatagonia argentina para la remoción de tiabendazol. Msc. Thesis. Universidad Nacional De San Luis. San Luis. Argentina. 2010.

39. Park. Y., Ayoko. G. A., Frost. R. L. Characterisation of organoclays and adsorption of p-nitrophenol: environmental application. Journal of Colloid and Interface Science, $2011,360,2,440-456$.

443

444 41. Zaki, M. I. et al. Ceria on silica and alumina catalysts: dispersion and surface

40. Lin-Vien. Daimay. et al. The Handbook of Infrared and Raman characteristic frequencies of organic molecules. Academic Press,1991. San Diego. acid- base properties as probed by $\mathrm{x}$-ray diffractometry, UV-Vis diffuse reflectance and in situ IRadsorption studies. Colloids and Surfaces A: Physicochemical and Engineering Aspects,1997,127, 1-3, 47-56. 
42. Joshi, G. V. et al. Montmorillonite intercalated with vitamin B1 as drug carrier. Applied Clay Science, 2009b,45, 4,248-253.

43. Nunes, C.D.et al. Load- Ing and delivery of sertraline using inorganic micro and mesoporous materials. European Journal Pharmaceutics Biopharmaceutics, 2007,66,357-365.

44. Mhlanga, N., Ray, S. S. Kinetic models for the release of the anticancer drug doxorubicin from biodegradable polylactide/metal oxide-based hybrids. International Journal of Biological Macromolecules, 2015,72,1301-1307.

456

45. Golubeva, O. Y., Pavlova, S. V., Yakovlev, A. V. Adsorption and in vitro release of vitamin b1 by synthetic nanoclays with montmorillonite structure. Applied Clay Science, 2015,112-113,10-16.

46. Peppas, N.A., Bures, P., Leobandung, W., Ichikawa, H. Hydrogels in pharmaceutical formulations. European Journal Pharm. Biopharm,200,50, 2746.

47. Munday, D.L, Cox, P.J. Compressed xanthan and karaya gum matrices: hydration, erosion and drug release mechanisms. International Journal of Pharmaceutics,2000,2031-2,179-192.

48. Tümsek. F., Avci. Ö. Investigation of kinetics and isotherm models for the acid orange 95 adsorption from aqueous solution onto natural minerals. Journal of Chemical and Engineering Data,2013,58,3,551-559. 